\title{
SHAREHOLDER REACTION TO CORPORATE WATER ACTIONS AND THE REPUTATIONAL EFFECTS OF CSR
}

\author{
RAFIA AFRIN \\ PhD Candidate, School of Business and Management, Queen Mary University of London, UK \\ NI PENG \\ School of Business and Management, Queen Mary University of London, UK \\ FRANCES BOWEN \\ Norwich Business School, University of East Anglia, UK
}

\begin{abstract}
This research presents an event study to investigate market reactions to corporate water actions and show that shareholders react positively to responsible water actions, and negatively to irresponsible actions. We also prove that these market reactions are influenced by previous good/bad general CSR performance that creates reputational capital/liability.
\end{abstract}

\section{INTRODUCTION}

Corporate water actions are a vital, but under-studied, dimension of corporate social and environmental performance. On the one hand, increasing global population and growing economies and industries are putting higher pressure on already depleted water supplies, and, on the other hand, water pollution is turning out to be a leading environmental problem, jeopardizing human health and ecosystems (Bowen, Bansal, \& Slawinski, 2018; Fogel \& Palmer, 2014; Lambooy, 2011; Boccaletti, Grobbel, \& Stuchtey, 2009). By 2030 water supplies are predicted to satisfy only about 60 percent of global demand (Boccaletti et al., 2009). Stakeholder awareness in this field appears to be increasing with time, with corporate water performance data being collected at an increasing rate on behalf of institutional investors (CDP, 2016).

The connection between corporate social responsibility (CSR) in general and corporate financial performance (CFP) has already been widely researched. Although the findings have varied, consolidating results through meta-analyses has mostly shown a positive relationship (Friede, Busch, \& Bassen, 2015; Margolis, Elfenbein, \& Walsh, 2007; Margolis \& Walsh, 2003; Orlitzky, Schmidt, \& Rynes., 2003). However, empirical evidence on how CFP connects with an important subset of CSR, that is, corporate water actions, is still quite inadequate (Whiteman, Walker, \& Perego, 2013). Therefore, we investigate this CSR-CFP link in context of corporate water actions, and also explore the effect of a firm's general CSR profile on stock market reactions to announcements relating to corporate water actions.

A particular contribution of our approach is that we investigate if and how this market reaction to a specific water action is moderated by the reputational advantages or disadvantages arising out of a company's good or bad general CSR participation in the immediate past. Some effects of this CSR reputation have already received research attention, especially the "insurance effect" proposed by Godfrey (2009) and "diminishing marginal returns effect" proposed by Flammer (2013), both applicable in the case of positive prior reputation. Both of these studies worked with particular types of CSR, and did not look at the general CSR participation by the 
firm as a composite construct. In our study we look at this composite CSR participation and complete the grid of effects, highlighting the notion that a firm participating in good and/or bad CSR actions might experience positive and/or negative reputation as a result, and these may coexist given the fact that the firm may have good actions and reputation in some CSR areas and bad in others. We term these reputational effects as reputational capital and reputational liability, and propose a two-by-two matrix relating these to abnormal stock returns from positive and negative water actions by firms, as shown in Table 1.

\section{INVESTOR REACTION TO CORPORATE WATER ACTIONS}

A good number of CSR theorists (Hart, 1995; Jones, 1995; Bansal \& Roth, 2000; Benabou \& Tirole, 2010) have argued that CSR creates important competitive advantages that can lead to increase in the profit potential of corporations and/or reduction of corporate risk (Peloza, 2006; Vilanova, Lozano, \& Arinas, 2009). Water actions in particular have been identified to be directly associated with business risk and crisis (Makower, 2013; Howell, 2013; Burton 2010). KPMG (2012) identified water scarcity as one of the 10 sustainability mega forces, with "water shortages, decline in water quality, water price volatility, and reputational impacts" being the main challenges for business organizations. Adriaens (2012) and Burritt, Christ, \& Omori (2016) noted this water risk can have serious impacts on corporate growth, market valuation, corporate creditworthiness, and bond rating.

While failure to perform satisfactorily across water parameters might expose organizations to these threat factors, responsible water stewardship might help organizations to turn the same factors into opportunities (Burritt et al., 2016; Jones, Hillier, \& Comfort, 2015). Just like any other branch of CSR, water can be an important area where shareholders and other stakeholders expect and reward responsible actions by business organizations and penalize irresponsible actions, in accordance with the enlightened stakeholder theory of CSR (Jensen, 2002). Prior research has shown that a number of stakeholders - including suppliers, investors, rating agencies, creditors, customers, communities, government, regulatory agencies, and NGOs, have started to take interest in water related actions and disclosure by firms (Burritt et al., 2016).

The opportunities associated with water can be expected to reflect positively and threats negatively, in the financial performance of organizations, by enhancing or mitigating return potential and risk factors (Oikonomou, Brooks, \& Pavelin, 2012; Aguinis \& Glavas, 2012). A few studies have already investigated the market reaction to CSR events and shown that investors react immediately to the release of new information (Hamilton, 1995; Konar \& Cohen, 1997; Flammer, 2013; Kruger 2015). However, no such study has been conducted in the context of water. We therefore propose the following hypotheses:

\section{Hypothesis 1 (a): Shareholders react positively to the announcement of a responsible (positive) water action.}

Hypothesis 1 (b): Shareholders react negatively to the announcement of an irresponsible (negative) water action.

\section{CSR AS REPUTATIONAL CAPITAL AND LIABILITY}


Past research has shown that CSR can create competitive advantage, just like any other tangible or intangible assets/resources owned by the firm (Branco \& Rodrigues, 2006; Simon, 1995). Though the company receives no explicit tangible exchange value against it, CSR can emerge as a strategic asset in the form of "reputational capital" (Fombrun, Gardberg, \& Sever, 2000) or "moral capital" (Godfrey, 2005). In this study, we take this idea forward and propose, just as a previous stock of good CSR performance can be a strategic asset, a previous stock of bad CSR performance can be a strategic liability and create negative moral or reputational capital. We therefore test whether previous CSR reputational capital or reputational liability affects stock market reactions to subsequent responsible or irresponsible corporate water actions.

\section{Effects of CSR reputational capital and reputational liability for positive water actions}

For companies that have already invested heavily in CSR and are enjoying high CSR reputational capital, we propose the marginal return from one additional CSR activity can be expected to keep decreasing after a point (top left quadrant of Table 1). Flammer (2013) provides evidence on diminishing marginal returns for environmental CSR. We extend the same notion to the reputational capital created by overall CSR participation and test whether the effect holds even when we look at a niche subset of CSR like water. We therefore, hypothesize:

Hypothesis 2: Shareholders react less positively to a positive water action for a firm with higher CSR reputational capital than for a firm with lower CSR reputational capital.

For companies that have previously engaged in negative CSR action/s and are facing high CSR reputational liability, the firm would have a direct impetus to change its corporate behavior in the immediate future, and shareholders would value and encourage that action more than if it seemed to have come out of nowhere (bottom left quadrant of Table 1). Kruger (2015) described this as "offsetting effect", based on which we propose:

Hypothesis 3: Shareholders react more positively to a positive water action for a firm with higher CSR reputational liability than for a firm with lower CSR reputational liability.

\section{Effects of CSR reputational capital and reputational liability for negative water actions}

The reputational capital of previous good CSR performance can be expected to provide mitigating or hedging benefits against negative market reactions in case of a subsequent negative CSR action by a firm (top right quadrant of Table 1). This "insurance effect" (Shiu \& Yang, 2015; Godfrey, 2009) created through the moral capital or goodwill of CSR helps the shareholders assess a subsequent negative action less severely:

Hypothesis 4: Shareholders react less negatively to a negative water action for a firm with higher CSR reputational capital than for a firm with lower CSR reputational capital.

We extend the same argument to claim that CSR reputational liability creates negative goodwill and additional risk factors for investors. This may lead to more severe or more negatively biased 
assessments of the firm when it gets involved in one additional negative action (bottom right quadrant of Table 1), and warrant more negative shareholder reaction:

Hypothesis 5: Shareholders react more negatively to a negative water action for a firm with higher CSR reputational liability than for a firm with lower CSR reputational liability.

\section{DATA ANALYSIS AND RESULTS}

To test our hypotheses, we manually collected news articles published in The Wall Street Journal and The Financial Times, featuring positive and negative water actions by firms, to construct a water event sample for S\&P 500 firms (as in 2017) from 2005 to June 2017. We used standard event study methodology to calculate the cumulative abnormal returns (CAR) to the firm around its water event date. We used KLD ESG data from MSCI to measure CSR performance, as a proxy for the CSR reputational capital and CSR reputational liability of the firm. To test for the effect of prior CSR reputation, we regressed water event CARs to the firm on its CSR reputational capital and CSR reputational liability, controlling for year and industry effect and a set of firm-level characteristics.

Our results show that the mean CAR is positive for positive events and negative for negative events (significant at a 1\% level), over different CAR windows, validating that there is a significant positive market reaction following a responsible water event and significant negative market reaction following an irresponsible water event. Our empirical analysis also provides significant evidence in favor of all four effects in our proposed matrix: diminishing marginal returns, offsetting effect, insurance effect, and punitive effect. In the case of positive water events, CSR reputational capital was found to share a negative relationship with stock market price reaction and CSR reputational liability was found to share a positive relationship with stock market price reaction. That is, high reputational capital attracted lower positive CAR than low reputational capital (diminishing marginal returns), and high reputational liability fetched higher positive CAR than low reputational liability (offsetting effects). Coming to negative water events, firms with high CSR reputational capital received strong insurance benefits as their fall in share price was much less than that for firms with low reputational capital. And finally, firms with high burden of reputational liability were penalized more heavily by the stock market than those with low reputational liability, highlighting the demerits of having previous CSR concerns.

Our results are robust over different CAR calculation windows and CAR calculation methods, and also over alternative calculation for CSR reputational capital and liability, adjusting KLD data in a meaningful way.

\section{CONCLUSION}

This study not only establishes the strategic and financial importance and stock market pay offs for corporate water actions, but also provides evidence that CSR in general can be an important strategic asset that can work as both reputational capital and reputational liability. This CSR reputation has strong effects that can influence market reactions when firms undertake subsequent positive or negative CSR actions, even in a niche field like water. Our analysis is useful to future researchers, providing new directions and focus for the study of corporate water actions. Also, our findings should help to convince all direct and indirect stakeholders of the 
market value of CSR actions, and incentivize optimal investment in both general CSR and specifically, water actions.

\section{REFERENCES AVAILABLE FROM THE AUTHOR}

Table 1: Effects of CSR Reputational Capital and Liability on Market Reaction to Corporate Water Actions

\begin{tabular}{|cc}
\hline $\begin{array}{c}\text { Market Reaction to } \\
\text { Positive Water Actions } \\
\left(\mathrm{y}_{1}\right)\end{array}$ & $\begin{array}{c}\text { Market Reaction to } \\
\text { Negative Water Actions } \\
\left(\mathrm{y}_{2}\right)\end{array}$ \\
\hline $\begin{array}{c}\text { H2: Diminishing Effect: } \\
\text { negative relationship } \\
\text { between } \mathrm{y}_{1} \text { and } \mathrm{x}_{1}\end{array}$ & $\begin{array}{c}\text { H4: Insurance Effect: } \\
\text { positive relationship } \\
\text { between } \mathrm{y}_{2} \text { and } \mathrm{x}_{1}\end{array}$ \\
$\begin{array}{c}\text { H3: Offsetting Effect: } \\
\text { positive relationship } \\
\text { between } \mathrm{y}_{1} \text { and } \mathrm{x}_{2}\end{array}$ & $\begin{array}{c}\text { H5: Punitive Effect: } \\
\text { negative relationship } \\
\text { between } \mathrm{y}_{2} \text { and } \mathrm{x}_{2}\end{array}$ \\
\hline
\end{tabular}

